\title{
POST-OPERATIVE USE OF THE SUFENTANIL SUBLINGUAL TABLET SYSTEM IN UROLOGIC MAJOR SURGERY - CASE SERIES.
}

\author{
Regêncio, M. \\ Department of Anaesthesiology and Pain Treatment of CETRUC - Centro de Tratamento \\ Urológico de Coimbra (Centre of Urologic Treatment of Coimbra), Coimbra, Portugal
}

Background and aims: Major urologic surgery is associated with significant post-operative pain, needing the use of high dose medication to control it ${ }^{1,2,3}$. After an excellent experience using sublingual sufentanil administration device in orthopedic surgery, we have decided to introduce this novel system as part of post-operative pain management in urologic surgery, aiming to demonstrate its effectiveness in pain control with minor side effects.

Methods: The sufentanil sublingual tablet system (SSTS) was used in 7 major urologic surgeries (1 radical prostatectomy; 3 retropubic prostatectomy; 1 subtotal cystectomy with appendicectomy and penile prosthesis removal; 1 partial right nephrectomy and 1 radical left nephrectomy). The anaesthetic technique used in all cases was balanced general anaesthesia. All patients received keterolac $(30 \mathrm{mg}, 8 / 8 \mathrm{~h}$, iv), during the first $48 \mathrm{~h}$. No postoperative nausea and vomiting prophylaxis was used. Numeric pain rating scale (NPRS), total analgesic consumption, haemodynamic variables and oximetry, adverse effects and patient satisfaction were assessed. NPRS was used on a twice a day basis, asking the patient to rate the maximum and average levels of pain, from the immediate postoperative period until the $72 \mathrm{~h}$ after starting the SSTS.

Results: Demographically, all patients were male; median age 65,1 years old (59-73); all started using SSTS upon arrival at the surgical ward. When asked to rate from 0 (very bad) to 10 (excellent) the satisfaction with the acute pain relief they received, the average was 9,4 (varying from 8 to 10 ).

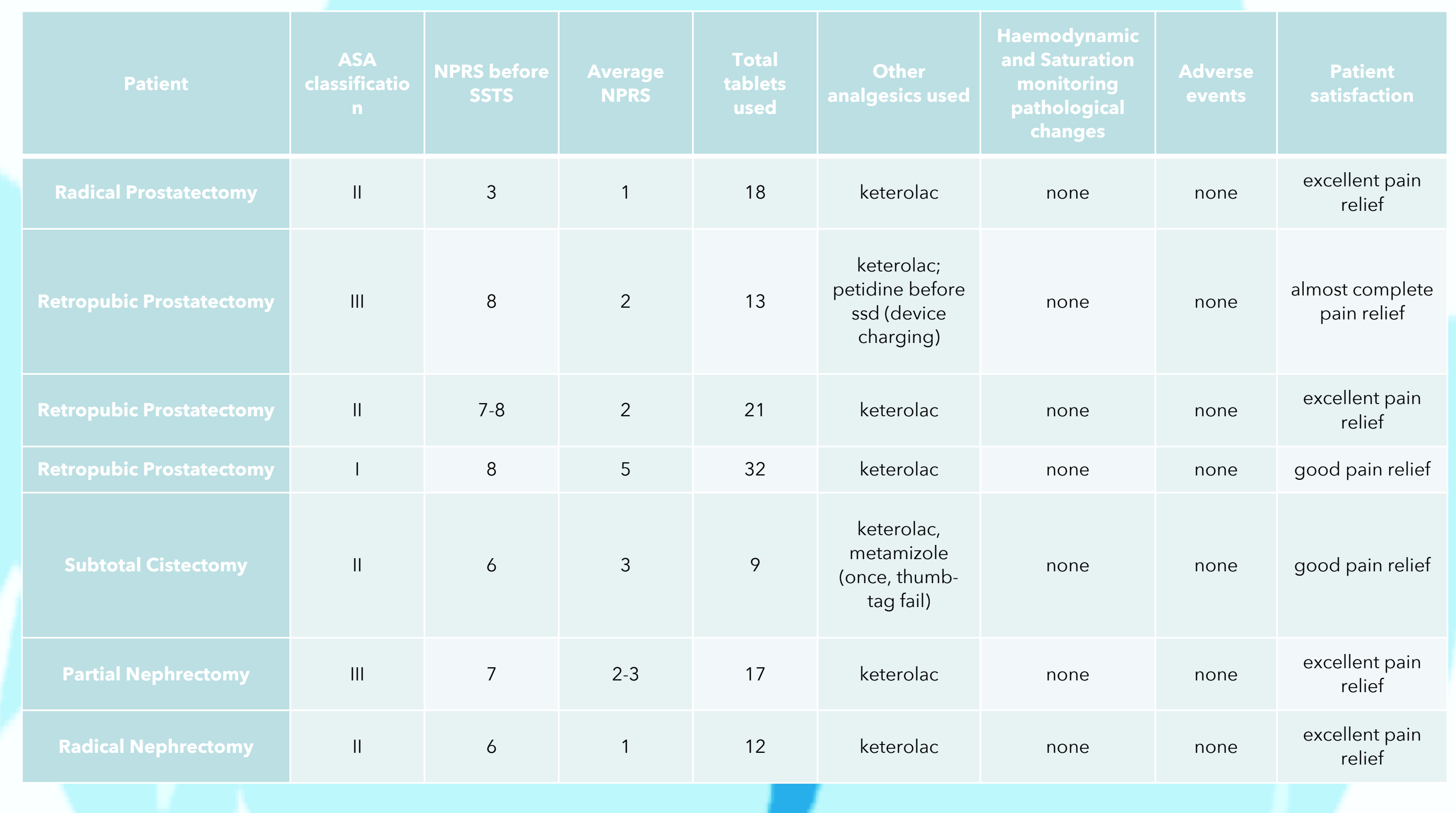

Conclusions: Our experience suggests that the sufentanil sublingual tablet system (SSTS) is a promising analgesic option in major urologic surgery. Even though we have a small sample of patients, this system has proven to be effective and safe when used. We have achieved a very good postoperative pain control, no adverse events were registered and few adjuvant analgesics were used. We will pursue with further prospective studies to quantify its advantages in a statistically significant level.

References

1.F. Heid and J. Jage, The treatment of pain in urology, BJU International (2002), 90, 481-488.

2.E. Akdeniz, M. S. Bolat and S. Akdeniz, Postoperative Pain Management in Urology, J Clin Anal Med 2015; DOI:

10.4328/JCAM 4013

3.M. Artus, B. Laviolle, A. Maurice; Y. Malledant and H. Bedoeil, Facteurs de risque de douleur postopératoire persistante après

chirurgie urologique (Risk factors for persistent pain after urological surgery), Annales Françaises d'Anesthésie et de éanimation,

Elsevier Masson, 2014, 33(5), pp. 89-94. 